$\begin{gathered}\text { Revista do Departamento de Geografia } \\ \text { Universidade de São Paulo } \\ \text { www.revistas.usp.br/rdg } \\ \text { Volume Especial (2016) }\end{gathered}$
ISSN 2236-2878

\title{
ADENTRANDO A CIDADE DE PELOTAS/RS PARA TOMAR-LHE A TEMPERATURA
}

\section{ENTERING THE CITY OF PELOTAS TO TAKE ITS TEMPERATURE}

\author{
Erika Collischonn \\ Universidade Federal de Pelotas \\ ecollischonn@gmail.com
}

Recebido (Received): 02/09/2016

Aceito (Accepted): 03/10/2016

DOI: $10.11606 /$ rdg.v1i0.121450

Resumo: Este artigo apresenta experimentos em clima urbano realizados na cidade de Pelotas inspirados nos esquemas propostos por Carlos Augusto de Figueiredo Monteiro. O primeiro experimento realizado no dia $13 / 09 / 2015$, baseado nos pressupostos teóricos da formação de ilhas de calor, buscou, através de medidas móveis, analisar a geração de diferenças térmicas no interior da cidade. $\mathrm{Na}$ medição noturna realizada, verificou-se ilha de calor com intensidade máxima de $5,4^{\circ} \mathrm{C}$ nesta cidade de porte médio. A disposição observada da ilha de calor mostra um núcleo na área central-sul e entradas de ar frio nos interstícios. O segundo experimento, realizado em 2014/2015, avalia o efeito do fator de visão do céu (FVC) sobre a temperatura do ar. Calculado o FVC para dez postos de coleta de temperatura e umidade do ar na cidade foi comparado o comportamento da temperatura e da umidade relativa do ar registradas. Foram seis períodos de registro intercalados e cada ponto de coleta contava com coletor eletrônico de dados. Os resultados mostram relação entre o microclima e o FVC. Nos levantamentos considerados os registros nos locais de maior obstrução foram em mais de $70 \%$ das vezes superiores à média. As áreas menos obstruídas foram as que apresentaram temperaturas abaixo da média.

Palavras-chave: Cidade; Temperatura do ar; Umidade do ar; Experimentos.

Abstract: This article presents experiments in an urban climate scenario, that were performed in the city of Pelotas and inspired by schemes proposed by Carlos Augusto de Figueiredo Monteiro. The first experiment, held on September 13th 2015, was based on theoretical assumptions of the heat islands formation and it sought, through mobile surveying, to analyze the creation of thermal differences in the middle of town. During a nighttime survey, a heat island of a $5,4^{\circ} \mathrm{C}$ maximum intensity was identified in the medium-size city. The observed heat island's spatial arrangement shows a core within the central-southern area and also cold air flows in the interstices. The second experiment, held during 2014-2015, evaluated the skyview factor (SVF) effect over the air temperature. The SVF was calculated for ten different intown temperature and air humidity registering stations, and it was compared afterwards to the air temperature and air humidity behavior. Six intersperse registering periods were held and each registering station had a datalogging device. The results show the relation between microclimate and the SVF. During the considered registering periods, the locations that were identified to be more obstructed were $70 \%$ of the times above temperature average. The less obstructed locations were the ones that showed below average temperatures.

Keywords: City; Air temperature; Air humidity; Experiments. 


\section{INTRODUÇÃO}

A paródia do título deste artigo expressa a nossa admiração e respeito pelo professor Carlos Augusto de Figueiredo Monteiro, porque o artigo "Adentrando a cidade para tomar-lhe a temperatura" - texto memorável da Revista Geosul número 9 - tornou-se um Leitmotiv desde que ensaiamos nossos primeiros estudos no Clima Urbano. Este artigo de Monteiro juntamente com o que o segue na mesma revista, intitulado "A cidade como processo derivador ambiental e a geração de um clima urbano - Estratégias na abordagem geográfica", tornaram-se cartilhas que seguimos e ainda perseguimos.

Este último artigo, Monteiro inicia com as considerações analíticas de uma avaliação geográfica do clima urbano, apresentando como fundamentais; a questão da escala, a inter-relação entre as escalas, a dimensão vertical e horizontal do fenômeno, o entendimento do sítio da cidade, bem como sua estruturação ao longo do tempo nas circunstâncias socioeconômica específica do país. A intelecção destes atributos seria, na proposta de Monteiro, antecedente necessário para compreender como a cidade é capaz de alterar as condições climáticas locais, até adquirir atributos tais que a possam dotar de um caráter de clima "urbano". $\mathrm{Na}$ segunda seção do mesmo artigo, Monteiro aborda proposição recorrente nos seus escritos, qual seja, o uso da modelização. Na terceira e última parte, o autor retoma o que expôs em "Teoria e Clima" como base para promover um espírito de corpo ou de grupo dos pesquisadores na criação da linha de pesquisa "Clima urbano". Desta forma, poder-se-ia ir além da etapa dos experimentos para atingir a etapa dos diagnósticos, os subsidio fundamentais ao monitoramento da qualidade ambiental.

Já no artigo cujo título foi parodiado aqui, Monteiro incentiva que o pesquisador assuma a observação direta e a produção de dados básicos da atmosfera intraurbana, já que dificilmente existem estes dados. O esquema que ele produziu aí, que foi por ele considerado uma "receita" ou "catecismo" que induziria mais a passividade repetitiva do que a atividade científica criadora serviu, nas pesquisas que realizamos, muitas vezes com recursos financeiros limitados, de estratégia para a análise do campo térmico nas cidades brasileiras.

Há sete anos exercemos atividades de ensino, pesquisa e extensão na Universidade Federal de Pelotas. Logo que assumimos foi-nos atribuída a condução da disciplina "Trabalho de Campo Integrado" para o Curso de Bacharelado em Geografia que então se iniciava. Porém, para esta disciplina ainda não havia equipamentos nem transporte disponível. A solução foi valer-nos da própria cidade como laboratório, integrar o que a literatura de referência traz sobre clima urbano com a especificidade de Pelotas e fazer uso de singelos instrumentos de medida (termo higrômetros e um clinômetro) e pequenos abrigos meteorológicos autoconfeccionados. Contudo, mais importante do que isso, foi que tínhamos os artigos da Geosul n.9, escritos numa linguagem fácil e convincente para levar qualquer iniciante geógrafo a apreender os primeiros rudimentos da pesquisa em climatologia urbana.

Começamos então os estudos do Clima Urbano de Pelotas, com experimentos em disciplinas ministradas na graduação e pós-graduação na UFPel, e que depois renderam um projeto financiado pela Fundação de Amparo a Pesquisa no Rio Grande do Sul e outro pelo CNPq. O tempo de vivência nesta cidade permitiu reconhecer de forma mais contundente o dinamismo de sua vida urbana e, inclusive, os tipos de tempo e sua sucessão de maneira a permitir uma abordagem mais certeira.

O que apresentamos neste trabalho, depois de definir a especificidade de Pelotas e de sua urbanização, são os resultados de experimentos de curto e longo prazo realizados neste contexto urbano seguindo em linhas gerais os ditames de Monteiro nos artigos já mencionados.

\section{CARACTERIZAÇÃO DA ÁREA DE ESTUDO}

Pelotas é uma cidade média com 318.872 habitantes (estimativa IBGE, 2015) localizada a $31^{\circ} 48^{\prime} \mathrm{S}$ e $52^{\circ} 19^{\prime}$ 'W, às margens do Canal São Gonçalo, curso que liga a Lagoa Mirim à Laguna dos Patos no estado Rio Grande do Sul, Brasil (Figura 1).

Em Pelotas o clima é controlado, principalmente, pela atuação das massas Polar (mP) e Tropical do Atlântico (mTa). O município tem verões quentes $\left(22,9^{\circ} \mathrm{C}\right.$ em média) e invernos frescos $\left(13,2^{\circ} \mathrm{C}\right.$ em média), como indicam as normais climatológicas da Estação Agroclimatológica de Pelotas (Figura 2) situada no Campus da Universidade Federal de Pelotas - UFPEL ( $\left.31^{\circ} 52^{\prime} \mathrm{S}, 52^{\circ} 21^{\prime} \mathrm{W}, 13,2 \mathrm{~m}\right)$. 


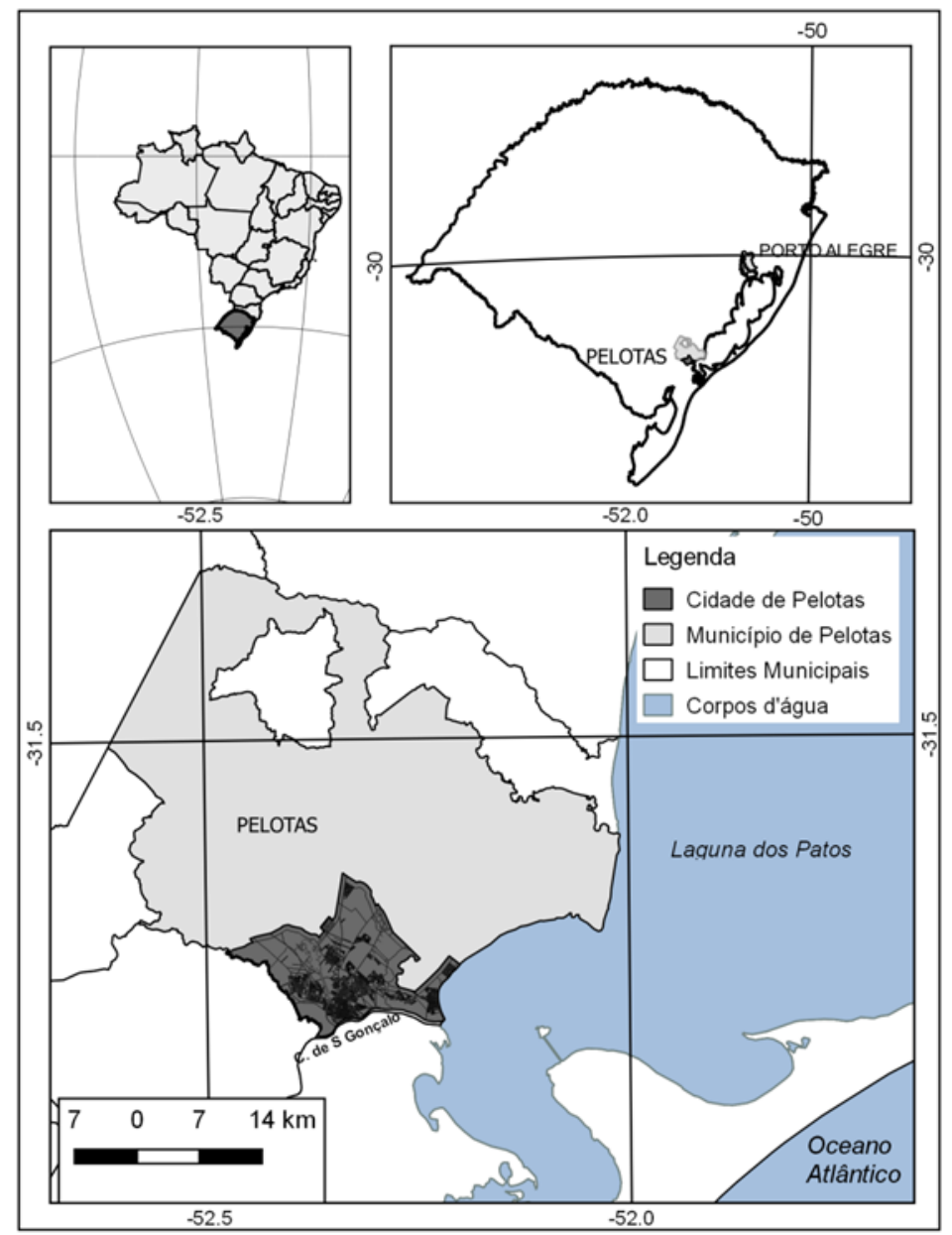

Figura 1: Localização da cidade de Pelotas, RS, Brasil.

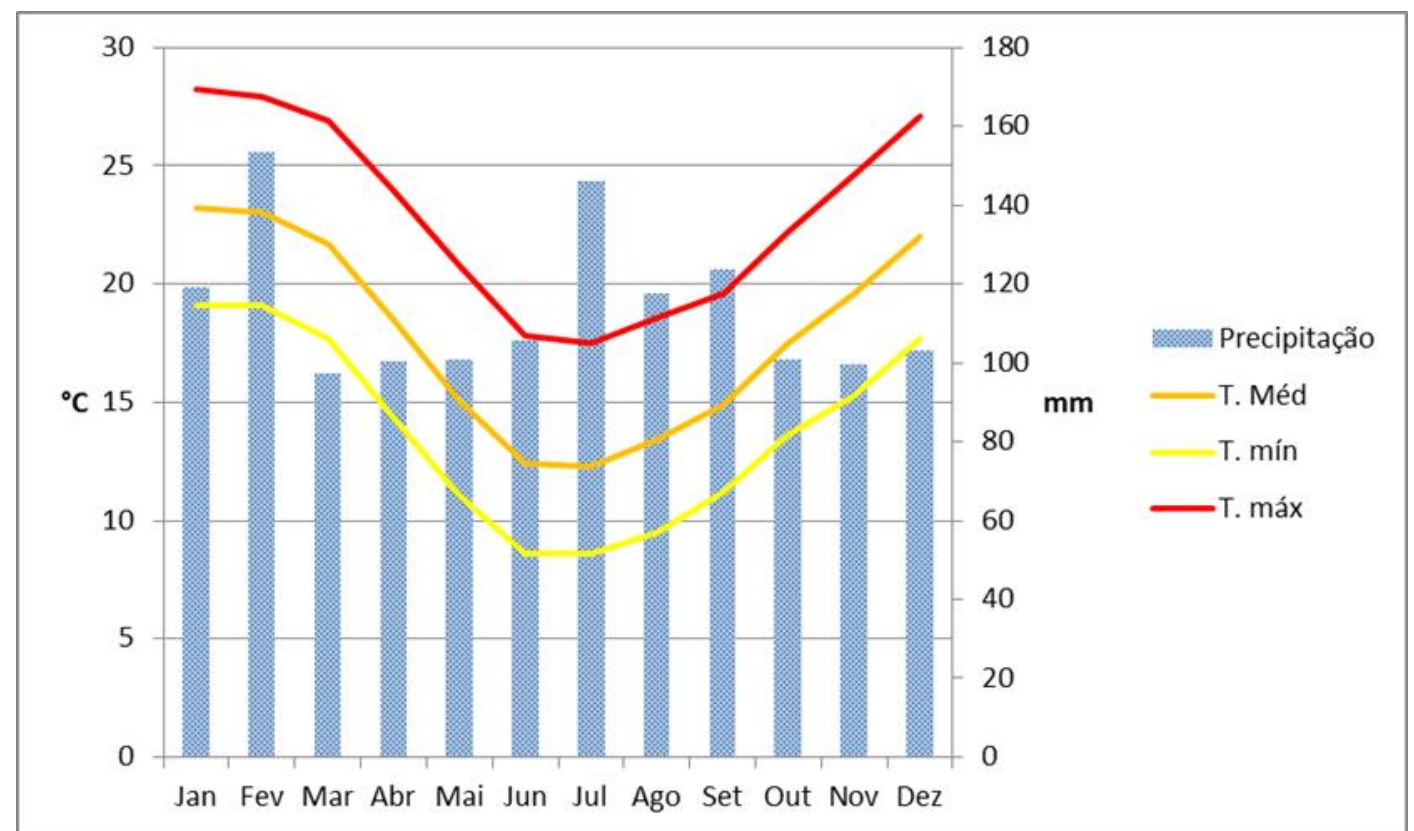

Figura 2: Normais Climatológicas 1971/2000 - Estação Agroclimatológica: Capão do Leão - RS. Fonte: http://www.cpact.embrapa.br/agromet/estacao/mensal.html (Organizado por Erika Collischonn) 
A passagem das frentes frias pode ocasionar bruscas mudanças no tempo atmosférico em qualquer estação do ano. Nos meses de outono, inverno e primavera, a frente, normalmente precedida por uma elevação de temperatura, é sucedida por ondas de frio das massas polares, com ocorrência de geada nas áreas menos urbanizadas (em média, 24 dias ao ano). No verão, a presença da massa polar é sentida pela mudança de direção dos ventos, que passam a soprar do quadrante sul e por uma agradável redução das temperaturas depois de dias de calor intenso. Também é próprio do tempo sob a ação da massa polar, a ocorrência de dias de maior amplitude térmica diária $\left(\right.$ até $12^{\circ} \mathrm{C}$ ) e umidade inferior a $50 \%$; porém, por influência da proximidade da Laguna e do Oceano, a umidade relativa média é alta $(75,5 \%$ em dezembro e $84,9 \%$ em julho).

Os sistemas frontais são ativos em todas as épocas do ano e regulam, tanto o ritmo das precipitações (as chuvas são geralmente pré-frontais, frontais ou pós-frontais), quanto o dos ventos. A velocidade média anual do vento é de $3,5 \mathrm{~m} / \mathrm{s}$. A média diária decresce no verão, até atingir um mínimo no outono $(2,7 \mathrm{~m} / \mathrm{s})$, voltando a crescer até atingir um máximo na primavera $(4,2 \mathrm{~m} / \mathrm{s})$. O vento que predomina durante o ano é leste, que também prepondera na primavera e no verão. Já no outono, a direção mais frequente é sudoeste e, no inverno, nordeste. Os ventos de máxima velocidade são os pré-frontais (NE) e pós-frontais (SW).

Como a altimetria na área de estudo varia entre dois metros, nas margens do Canal São Gonçalo, e vinte metros, a altitude não pode ser considerada um controle essencial na definição de diferenciações climáticas intraurbanas. Também não é relevante o efeito de orientação de vertentes, fundamental na maior ou menor recepção da radiação, nem o de canalização físico-natural de vento, ainda que existam no contexto da cidade alguns baixios que possam se tornar áreas de acúmulo de ar frio em dias sem vento no inverno.

Como cidade média, Pelotas oferece um leque bastante largo de comércios e serviços especializados, estando assim em interação constante com as áreas coloniais e cidades menores do espaço regional a ela ligado; também recebe constantemente migrantes de cidades menores ou da zona rural, que aí se fixam. Assim, o espaço intraurbano de Pelotas se caracteriza por um centro funcional bem individualizado e uma periferia dinâmica, que evolui segundo um modelo bem parecido com o das grandes cidades. Isto é, através da multiplicação de novos núcleos habitacionais periféricos, bastante dependentes do centro funcional. O Centro, durante o dia, concentra pessoas, veículos e usos intensos da terra. Ainda assim, Pelotas não apresenta crescimento vertical significativo, expandindo-se por aglomerações residenciais horizontalizadas que fazem o tecido urbano se dissolver para limites cada vez mais amplos. A partir do centro urbano tradicional (Praça Coronel Pedro Osório), a cidade se espraia por cerca de $7 \mathrm{~km}$ para o norte (bairro Três Vendas), $6 \mathrm{~km}$ para o oeste (bairro Fragata), 1,5 km para o sul (Porto), $4 \mathrm{~km}$ para leste (bairro Areal), sem considerar o Bairro Laranjal à beira da Lagoa dos Patos, que dista $11 \mathrm{~km}$ do centro. Assim o perímetro urbano de Pelotas apresenta uma ocupação horizontal extensa $(192.65 \mathrm{~km} 2)$, compacta próximo aos eixos viários principais e menos densa nos interstícios, onde ainda são frequentes os alagadiços e áreas de uso agrícola (Figura 3).

A partir da figura pode-se ter uma ideia das áreas de maior e menor densidade construída. A partir de dados do cadastro técnico da prefeitura de base geográfica de lotes e área total construída bruta, foi possível obter o coeficiente de aproveitamento (CA). Sendo este índice calculado pela relação de área construída com área do lote da unidade. De acordo com os dados fornecidos pela prefeitura, a concentração de maiores densidades construídas é observada na área central (tons terrosos na Figura 3). Densidades com valores a partir de 2,5, conformam tipologias de ocupação de 3 pavimentos ou mais. Por ser uma cidade com um patrimônio em construções do século XIX preservado, a densidade construída, mesmo na área central, é mais baixa se comparado a outras cidades. 


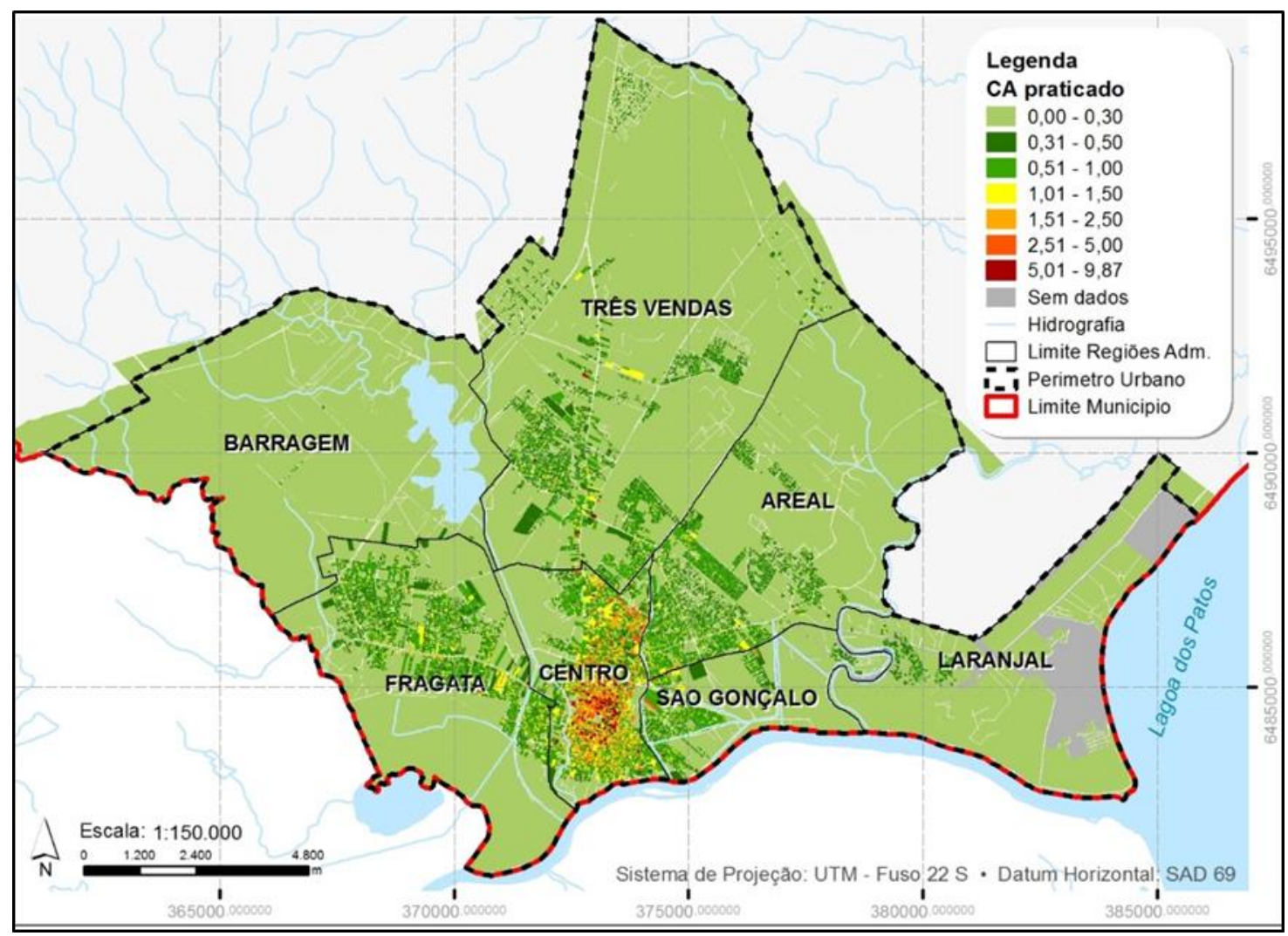

Figura 3: Mapa de Densidade Construída Urbana de Pelotas. Fonte: Dados PMP, 2015 (Organização Lúcia Lopes).

\section{PRIMEIRO EXPERIMENTO}

Este experimento foi desenvolvido como prática de disciplina na área das geotecnologias no Mestrado em Geografia da UFPel, principalmente com o objetivo de transformação de dados do tipo objetos discretos em dados do tipo campos contínuos. O desafio foi avaliar, a partir de dados discretos, diferenças termo-higrométricas na área intraurbana e a existência e intensidade de ilha de calor na cidade de Pelotas.

Em artigo de 1974, de Oke e Hunnell (apud BASCÓN, 1999) relacionaram a amplitude máxima da ICU com a população do núcleo urbano, em cidades de clima temperado, por meio da fórmula matemática (1).

\section{$\Delta(\mathrm{u}-\mathrm{r}) \max =2,01 * \log (\mathrm{P})-4,06$}

Onde:

$\mathrm{u}=$ temperatura urbana; $\mathrm{r}=$ temperatura rural; $\mathrm{P}=$ população urbana

De acordo com esta fórmula empírica, para uma cidade de 318.109 habitantes, como Pelotas, o valor máximo da ICU deveria ser de $7^{\circ} \mathrm{C}$.

Para Longley et al (2012), as duas formas fundamentais de representação geográfica são os objetos discretos e os campos contínuos. Segundo ele, na visão de objetos, o mundo geográfico se distingue em unidades que possuem limites bem definidos sem gradação ou continuidade entre si; já na visão de campo contínuo, o mundo real é representado como um número finito de variáveis cambiantes, que podem ser discriminados pelo que está sendo medido em cada ponto/variável.

Na representação em campos contínuos, segundo Câmara et al. (2005), o mundo real é visto como uma superfície contínua sobre a qual entidades geográficas variam gradativamente relacionadas a fatores ou outras variáveis. Normalmente, fenômenos naturais, físicos ou biológicos são representados por variáveis contínuas, como é o caso para a temperatura e umidade do ar. Na visão de objetos, segundo o mesmo autor, a realidade é vista como uma superfície ocupada por entidades identificáveis que possuem uma determinada posição, geometria e características próprias. Portanto, todas as posições no espaço geográfico inseridas na feição ou objeto considerado estão associadas ao mesmo valor correspondente à variável representada. 
Para Borges (2002), um objeto contém um dado individual, que por sua vez possui atributos que o distinguem dos demais. Assim, dados de temperatura e umidade do ar coletados em estações meteorológicas ou mesmo locais diferenciados numa cidade são dados discretos, porque correspondem àquele ponto de levantamento. Para construir uma representação da distribuição destas variáveis em campos contínuos, a amostragem por pontos modelará o espaço como um conjunto dos mesmos, e estes, com seus respectivos atributos, serão usados para construir sua relação com os demais pontos. Nas sequencia, se descreve como foi desenvolvido este experimento de criação de uma representação em campo contínuo a partir de dados amostrais obtidos em campo.

\section{PROCEDIMENTOS METODOLÓGICOS DO PRIMEIRO EXPERIMENTO}

O método utilizado para medir a temperatura a umidade do ar e o vento nos pontos amostrais, foi o de medidas móveis referenciadas a uma estação fixa. Utilizado pela primeira vez em 1927 na Áustria e introduzido no Brasil por Hasenack et al. (1982), as medidas móveis, segundo Gartland (2010, p. 40) são uma maneira econômica de estudar as variações térmicas numa cidade e implicam em percorrer um trajeto determinado, parando em locais representativos para obter medidas utilizando instrumentação meteorológica básica. O método consiste na fixação do equipamento a um veículo automotor trafegando a uma velocidade constante e relativamente baixa, entre $20 \mathrm{~km} / \mathrm{h}$ e $50 \mathrm{~km} / \mathrm{h}$. No experimento realizado não foi ultrapassada a velocidade de $30 \mathrm{~km} / \mathrm{h}$.

Monteiro (1990a) propôs a realização de medidas por transectos em vias que atravessam a cidade, saindo da periferia (rural), passando pelo centro e chegando ao extremo oposto da cidade. Esta metodologia foi adaptada para medidas móveis por Amorim et al. (2009).

No experimento realizado em Pelotas, as medidas móveis de temperatura e umidade foram realizadas com base em amostragem. Considerou-se como base inicial uma grade regular de pontos com equidistância de $500 \mathrm{~m}$. Esta foi sobreposta como uma camada $(\mathrm{kml})$ à imagem do Google Earth. Nesta sobreposição, constatou-se que alguns desses pontos ficavam em área inatingível; assim, por conveniência, foi realizada uma readequação da grade às vias existentes. $\mathrm{Na}$ área central da cidade, mais verticalizada, foram marcados alguns pontos intermediários, de forma que, chegou-se a mais de 100 pontos amostrais. Em cada um dos pontos amostrais percorridos foram registrados dados.

Os manuais recomendam que as aquisições móveis sejam realizadas em horários de temperaturas mais estáveis, distantes do nascer e pôr do sol. Neste experimento, as medidas foram realizadas entre as $21 \mathrm{~h}$ e 23h, do dia 13/09/2015. Para o levantamento de campo foram definidas duas equipes, uma para cada região parcial de significativa ocupação urbana de Pelotas e divididas pelas Regiões Administrativas (RA). Sendo uma equipe disposta para coleta nos bairros Centro, Porto e Fragata, e outra equipe para os bairros Três Vendas, Areal e São Gonçalo. As RA Barragem e Laranjal, não foram incluídos no levantamento pela baixa ocupação e por riscos de comprometer o levantamento pelas longas distancias.

Como os dados precisavam ser referidos a um ponto de coleta fixo, este foi instalado num pátio no centro da cidade. Este posto se refere a um tripé sobre o qual foi fixado pequeno abrigo, leve, de pouca resistência térmica, no interior dos quais se suspende o Datalogger. Visando a padronização da distância do solo para a medição, o instrumento registrador foi disposto a $1,5 \mathrm{~m}$ do solo e foi programado para armazenar dados automaticamente a cada minuto, no intuito de ser usado como referência para as medidas móveis.

Programados os intervalos de registro de dados a cada minuto, os Datalogger para o levantamento de medidas móveis foram colocados num suporte preso com uma ventosa sobre o teto dos veículos (Figura 4). Os aparelhos registradores foram montados aproximadamente 20 minutos antes do início do levantamento de dados, a fim de permitir que houvesse tempo para ambientação externa. Com o intuito das equipes perceberem a variação de temperatura e umidade na cidade foi também acoplado um sensor fora do veículo que, através de um cabo, permitiu a leitura num visualizador analógico. 


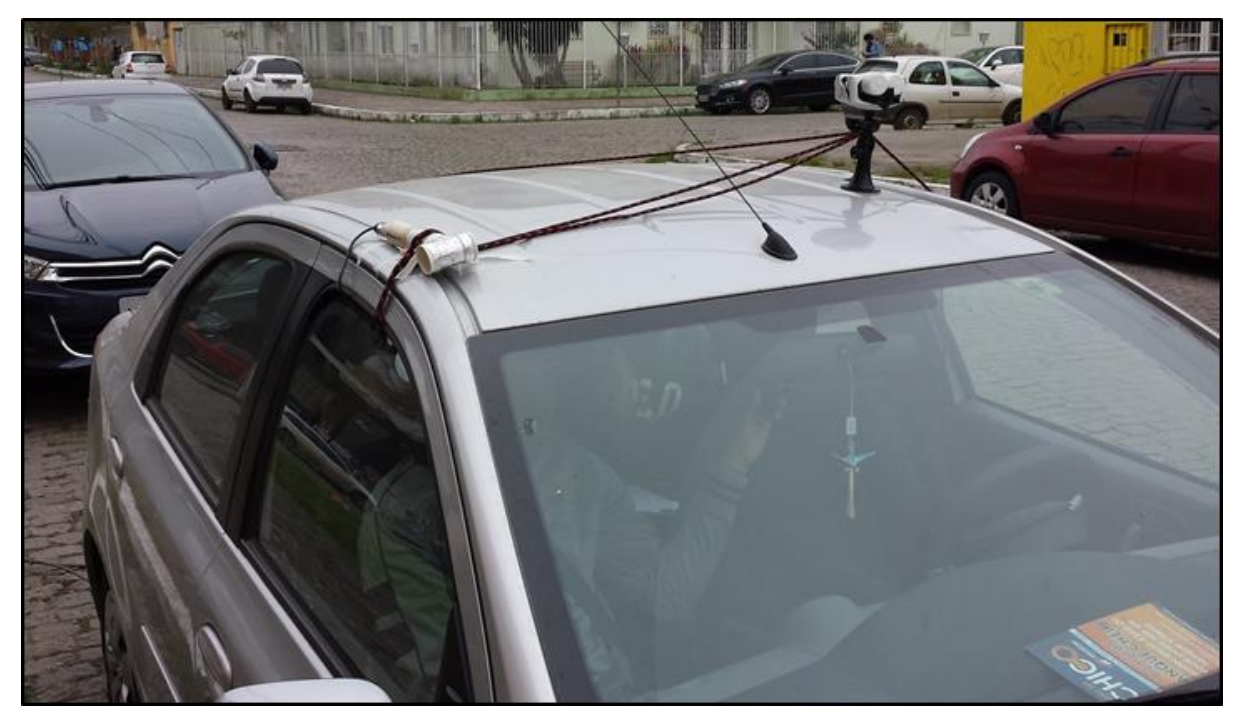

Figura 4: Equipamento de medição acoplado ao veículo automotor. Foto de Erika Collischonn, 2015.

O levantamento de dados foi realizado na noite de 13/09/2015, das $21 \mathrm{~h}$ às $23 \mathrm{~h}$. Os sistemas atmosféricos regionais que atuaram no dia de levantamento de campo foram analisados por meio de cartas sinóticas de superfície disponibilizadas no site da Marinha do Brasil e das imagens de satélite GOES-13 disponibilizadas pelo Instituto Nacional de Pesquisas Espaciais.

No dia 10/09/2015 uma massa de ar frio de origem polar havia chegado ao Rio Grande do Sul, proporcionando depois da passagem do Sistema Frontal uma sequência de madrugadas muito frias para a época do ano no Estado. Segundo a Metsul (2015), o anticiclone polar se originou no Mar de Bellingshausen na Antártida trazendo ar gelado ao Sul do Brasil, ao Norte da Argentina e ao Paraguai. Este tipo de invasão de ar polar costuma produzir frio bastante intenso, como de fato ocorreu. No sábado 12/09, sob o domínio anticiclônico, a temperatura mínima foi de $1,8^{\circ} \mathrm{C}$ e a máxima de $17,4^{\circ} \mathrm{C}$, enquanto a umidade apresentou uma média de $53 \%$ na estação agroclimatológica de Pelotas. Durante o domingo $13 / 09$, a mínima foi de $4,4^{\circ} \mathrm{C}$, máxima já foi para $21,8^{\circ} \mathrm{C}$ e a umidade media ficou em $61 \%$. No dia $13 / 09$, a formação de uma linha de instabilidade no Atlântico definiu ocorrência de ventos de norte-noroeste à tarde, porém, à noite quando foi realizado o levantamento, não houve vento.

Em campo, a cada 2 minutos, foi marcado um ponto de coleta no GPS e, numa planilha em papel, realizado o registro com o identificador do ponto, o horário de leitura e também a temperatura e a umidade do ar indicadas pelo visualizador analógico. $\mathrm{O}$ total de pontos para os quais foram gravadas as coordenadas, coletados e processados os dados de temperatura e umidade do ar foi de 127 pontos. Depois do levantamento, foi realizada a leitura ótica dos dados dos instrumentos usados nas medidas móveis; em seguida, foi realizada a leitura ótica dos dados do registrador de referência; e, por fim, os dos demais locais de coleta fixos. Os dados brutos de cada instrumento foram organizados em uma planilha. Também os dados do GPS foram transferidos para o computador e transformados em planilha, na qual foi possível identificar o horário de registro de cada ponto.

A partir do horário indicado na planilha de registros do instrumento identificou-se o ponto de coleta correspondente no GPS, que foi usado como identificador do ponto. Os valores registrados no ponto fixo também foram introduzidos em planilhas e utilizados como valor referência no momento dos registros em cada ponto de coleta. Para uma leitura mais direta da detecção da variação de temperatura ao longo da mancha urbana foram calculadas as diferenças relativas de temperatura e de umidade do ar de cada ponto de observação, com referência ao posto fixo mais central, conforme proposto por Hasenack et al. (2003).

Os pontos de coleta com seus devidos atributos (temperatura, umidade e diferenças relativas) foram espacializados, compondo camadas em ambiente de geoprocessamento (QGIS), a fim de possibilitar a análise espacial e cruzamento com as características da ocupação urbana da cidade de Pelotas. Para a criação de um campo contínuo de distribuição destes dados em células o método de interpolação utilizado foi o inverso da distância ponderada (IDW). O interpolador IDW calcula os valores das células desconhecidas, a partir da distância ponderada de pontos conhecidos (amostrais), mediante um coeficiente que controla a influência da ponderação segundo o aumento da distância de pontos desconhecidos (MIRANDA,2005, p.285). 


\section{RESULTADOS DO PRIMEIRO CAMPO}

Com o intuito de relacionar o comportamento da temperatura urbana com a característica de ocupação, a fim de compor os mapas de temperatura e umidade, foram calculadas as diferenças relativas ao ponto fixo mais central. Esta medida buscou eliminar as variações decorrentes do processo de resfriamento noturno durante o período de registros. Ainda para facilitar a leitura, os valores foram normalizados considerando o menor valor (negativo) como valor zero, uma vez que o ponto fixo está localizado em uma posição de maiores valores de temperatura. Assim, tem-se um intervalo de zero ao máximo da variação medida (Figura 5).

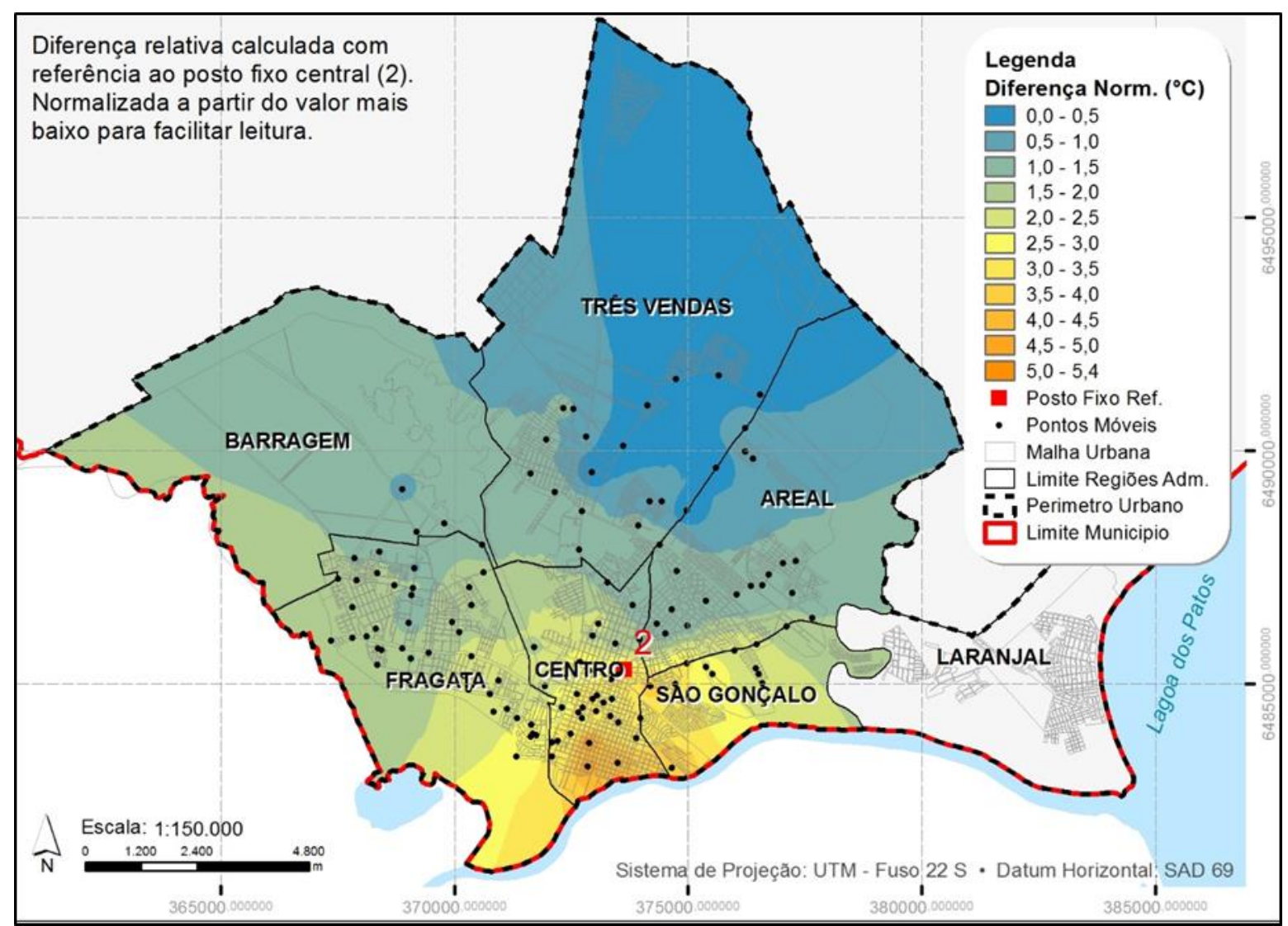

Figura 5: Diferença de Temperatura relativa ao ponto fixo normalizado na noite do dia 13/09/2015. Levantamento de campo (Organização Lúcia Lopes).

Na noite de 23/09/2015 constatou-se, na parte amostrada do perímetro urbano de Pelotas, uma diferença de temperatura de $5,4^{\circ} \mathrm{C}$. O mapa indica uma relação da característica da ocupação (Figura 3) e, como todas as condições atmosféricas já mencionadas anteriormente. Uma variação significativa também pode ser notada na umidade, de quase $30 \%$ do centro para as áreas mais periféricas ao norte da área urbana. A posição da ilha de calor mais deslocada para o centro sul da cidade pode ter uma relação com a brisa NNO que soprou à tarde.

Conforme a fórmula empírica apresentada no início do trabalho, uma cidade com número de habitantes igual ao de Pelotas, deveria apresentar uma ilha de calor de no máximo $7^{\circ} \mathrm{C}$. Pelos resultados obtidos no exercício realizado, num dia não totalmente propício, chegou-se a diferenças térmicas de até $5,4^{\circ} \mathrm{C}$. Portanto, o valor identificado não extrapolou o previsto nas referências estudadas.

Como exercício de aprendizagem, o experimento foi eficiente na criação de metodologia que exigiu o uso de ferramentas de geoprocessamento desde a definição da amostragem até a interpolação final dos dados. Contudo, para se chegar a informações mais contundentes sobre o clima urbano de Pelotas, no sentido de propor medidas mitigatórias do desconforto térmico, o mesmo experimento deveria ser repetido pelo menos duas vezes a cada estação do ano e, também, em diferentes tipos de tempo. 
Em relação aos mapas obtidos por interpolação, Monteiro (1990a, p.71) chama atenção para o cuidado com os pontos de amostragem e propôs que fossem definidos círculos em áreas nas quais as características urbanas e de topografia fossem homogêneas. Em seguida, dentro de tais círculos, seriam realizadas três medidas cuja média definiria o registro da amostra. Ele também definiu que fosse possível a esta estratégia contrapor-se ou adicionar o índice de obstrução do céu. O efeito do índice de obstrução do céu ou fator de visão do céu é o que se apresenta no experimento que segue.

\section{SEGUNDO EXPERIMENTO}

Uma das análises mais difíceis em climatologia é a modelagem dos processos de transferência de energia no meio intraurbano. A ilha de calor urbana, anteriormente citada, é resultado das ações de diversas variáveis. Dentre elas, a geometria das estruturas urbanas modificam o horizonte visível e os fluxos de radiação recebidos. Segundo Oke (2006), as construções urbanas, pela sua geometria, favorecem a maior absorção de onda curta e contribuem para a diminuição da perda líquida de radiação de onda longa, devido à redução do horizonte local.

Uma forma de avaliar o efeito da geometria urbana pode ser obtida pelo Fator de Visão do Céu (FVC) (SWENSON, 2004; HÄMMERLE et al. 2011). O valor do FVC varia de 0 (zero) a 1, sendo o valor 1 correspondente a uma área sem qualquer obstáculo que se interponha entre o ponto escolhido e o céu. Diferentes FVC significam diferentes balanços de radiação e, consequentemente, diferentes armazenamentos de energia. Um local com FVC igual a 1 (sem nenhuma obstrução) sob condições de céu claro, recebe radiação de onda curta durante o dia todo e emite radiação de onda longa à noite. Já um ambiente mais obstruído, normalmente, recebe menos radiação de onda curta diretamente, mas pode recebê-la por reflexão de paredes ou outras estruturas, além de estar suscetível a radiações adicionais de ondas longas provenientes destas superfícies. Assim pode se aquecer mais e, principalmente, prolongar o período de emissão à noite.

Um estudo posto em prática nos anos $1980 \mathrm{em}$ cidades de pequeno e médio porte próximas a Tóquio no Japão ( $\left(35^{\circ} 40^{\prime} \mathrm{N}\right.$ ) por Yamashita et al. (apud MINELLA et al, 2011, p. 124), buscou relacionar as ilhas de calor com o tamanho das cidades. Durante os experimentos, foram realizadas medições diurnas e noturnas, em todas as épocas do ano. Nas cinco cidades monitoradas foram verificadas diferenças de temperatura do ar entre as áreas mais adensadas e menos adensadas. O FVC foi considerado um indicador fundamental para expressar os efeitos da urbanização sobre a intensidade da ilha de calor. Monteiro (1990, p. 69) também aponta duas vantagens desta técnica "a primeira é a homogeneização das dimensões da área de observação obtida rigorosamente, pela mesma lente acima dos pontos. A segunda é que o que aparece dentro do círculo, significando um sinal de "obstrução" pode ser considerado como algo passível de ser qualificado". Em Pelotas foi realizada uma avaliação similar com apoio financeiro do CNPq durante os anos de 2014 e 2015.

\section{PROCEDIMENTOS METODOLÓGICOS DO SEGUNDO EXPERIMENTO}

Durante os anos de 2014 e 2015 foram instalados termo-higrômetros de registro contínuo, por períodos de 15 a 21 dias, intercalados por períodos sem registro, em dez ambientes distintos na área urbana. Os locais variaram de características de entorno e posição, desde a beira do canal de São Gonçalo até os bairros residenciais mais periféricos, passando pela área de uso mais intenso no centro da cidade.

A escolha dos locais de registro de temperatura e umidade do ar na cidade de Pelotas foi realizada com base naquilo que se assume perceptível através da simples observação cotidiana. Isto é, estabeleceramse as localidades em pontos dispersos que permitissem expressar as especificidades existentes na cidade de Pelotas. Para a avaliação de seu efeito sobre as trocas térmicas, contudo, o fator segurança nos locais também foi levado em conta. A Figura 6 apresenta a localização de cada um dos abrigos contendo o instrumento registrador de temperatura e umidade. A Figura 7 é uma composição das fotografias de cada um dos locais de coleta, conforme a mesma numeração. Dispostos nos abrigos, os instrumentos registradores de temperatura e umidade relativa do ar (datalogger - Onset U23001) foram programados para que os dados fossem automaticamente armazenados a cada 30 minutos. 


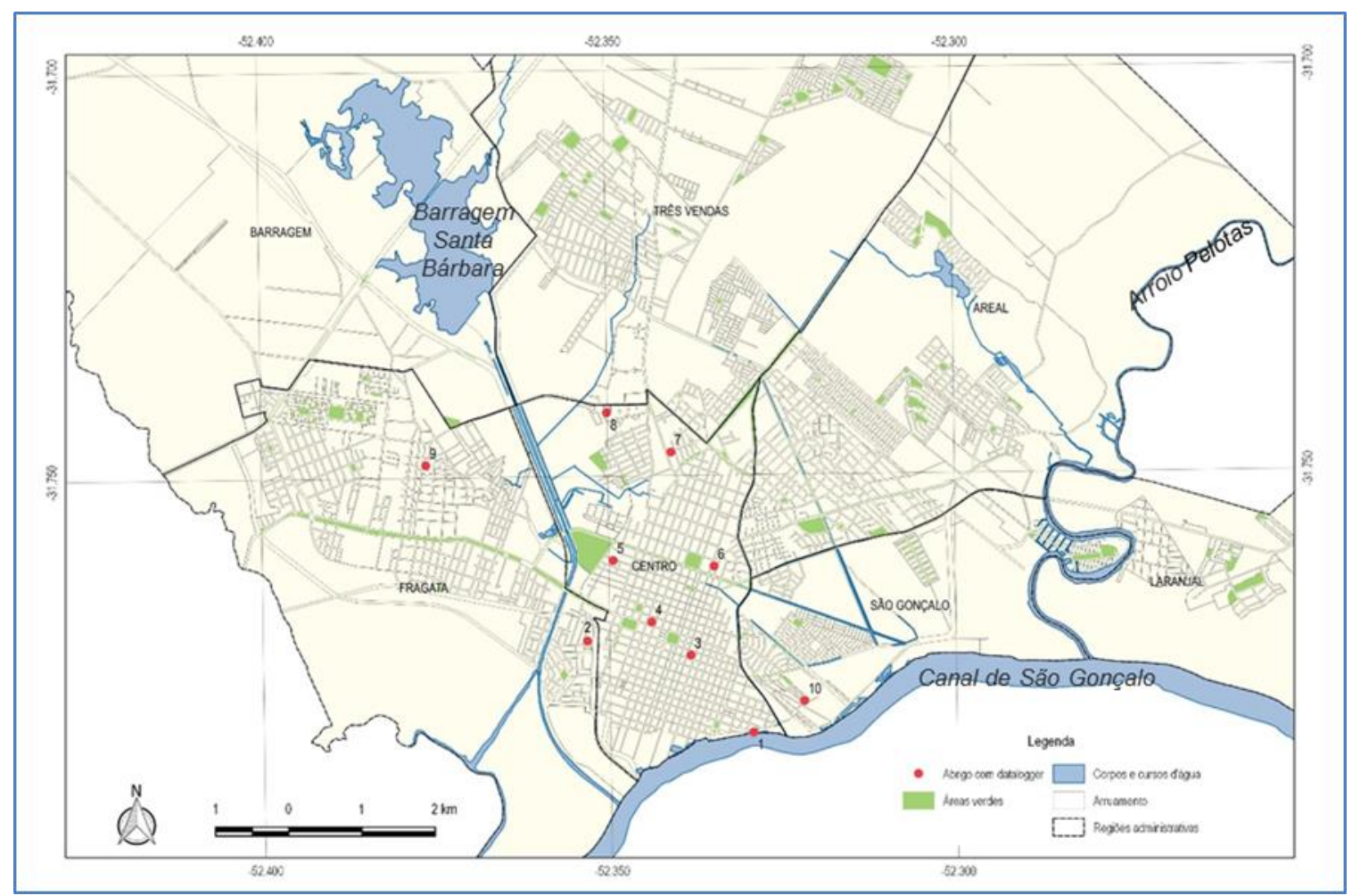

Figura 6: Distribuição dos miniabrigos na cidade de Pelotas - RS.

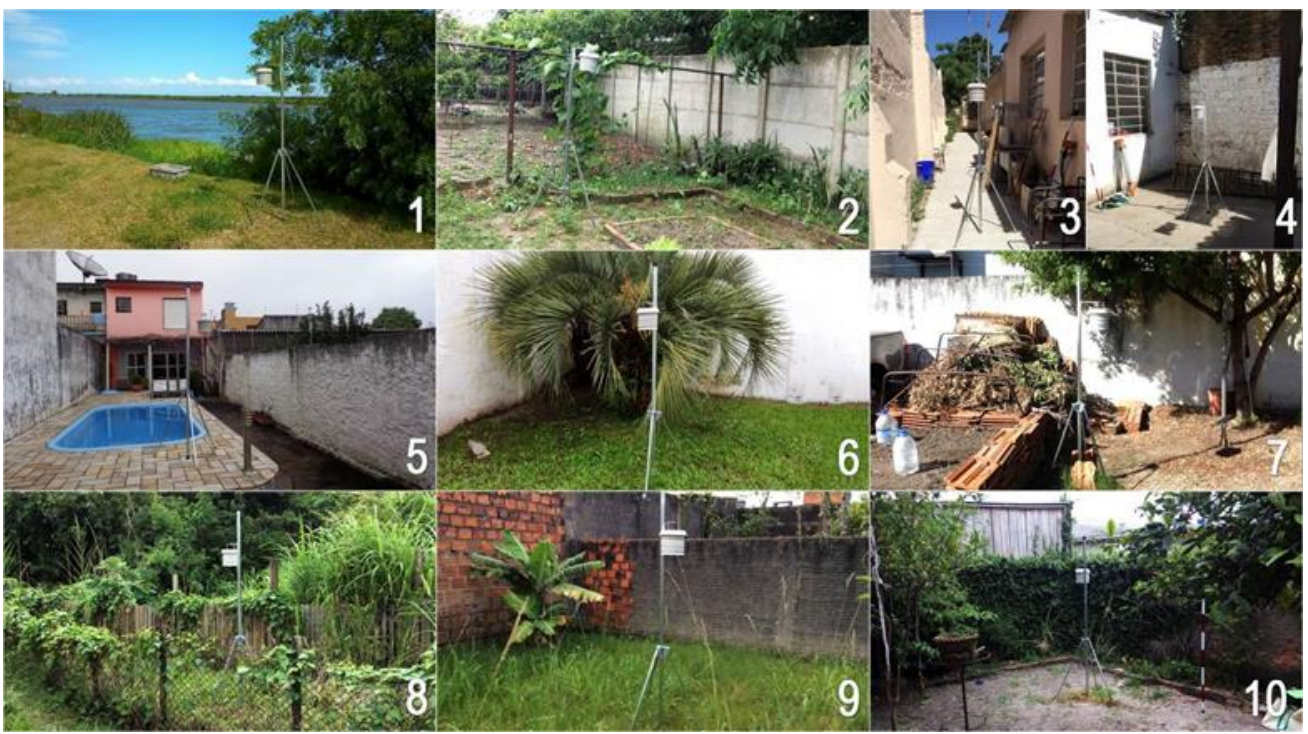

Figura 7: Fotografias dos 10 miniabrigos meteorológicos com numeração correspondente.

Com o auxílio de um aplicativo específico disponibilizado pelo Departamento de Ciências da Terra da Universidade de Gotemburgo, foi realizado ainda o cálculo do FVC de cada um desses locais de coleta. Esta metodologia foi explicitada em trabalho anterior (COLLISCHONN et al., 2015). Para avaliar com mais propriedade esta quantificação apresenta-se também figura com a silhueta de obstrução do horizonte dos pontos de coleta acrescida do traçado da trajetória do sol no céu em diferentes épocas do ano. No intuito de compreender melhor como a urbanização está interferindo na chegada e saída de energia em cada local de coleta de dados, a seção seguinte apresenta a relação do fator de visão do céu com o comportamento termo higrométrico médio dos levantamentos realizados. 


\section{RESULTADOS DO SEGUNDO EXPERIMENTO}

Com base nos resultados para os dez pontos de coleta na cidade de Pelotas, foram definidas três classes de obstrução (Tabela 1), sendo estas: locais com alta obstrução, apresentando FVC entre 0 e 0,400; locais com obstrução moderada, que possuem FVC no intervalo entre 0,401 a 0,700; e, por fim, locais de baixa obstrução aqueles com FVC na faixa de 0,701 a 1.

Tabela 1: Resultados calculados de fator de visão do céu das estações de registro.

\begin{tabular}{c|cccccccccccc}
\hline \multicolumn{4}{c}{ Obstrução Alta } & \multicolumn{4}{c}{ Obstrução Moderada } & \multicolumn{3}{c}{ Obstrução Baixa } \\
\hline Estação & 4 & 3 & 1 & 2 & 10 & 7 & 5 & 6 & 8 & 9 \\
\hline FVC & 0,339 & 0,385 & 0,399 & 0,433 & 0,562 & 0,659 & 0,678 & 0,682 & 0,842 & 0,864 \\
& & & & & & & & & & \\
\hline
\end{tabular}

Para avaliar com mais propriedade esta quantificação apresentamos a silhueta de obstrução do horizonte das mesmas estações com a trajetória do sol no céu em diferentes épocas do ano (Figura 8). Na latitude $31,75^{\circ} \mathrm{S}$ já é fundamental considerar em que direção o horizonte está obstruído, porque os raios solares nesta latitude voltam-se mais para o horizonte norte e, no solstício de inverno, apresentam um ângulo de no máximo $34,75^{\circ}$. Assim, um horizonte norte obstruído afeta muito mais a chegada de energia solar do que um horizonte sul obstruído.

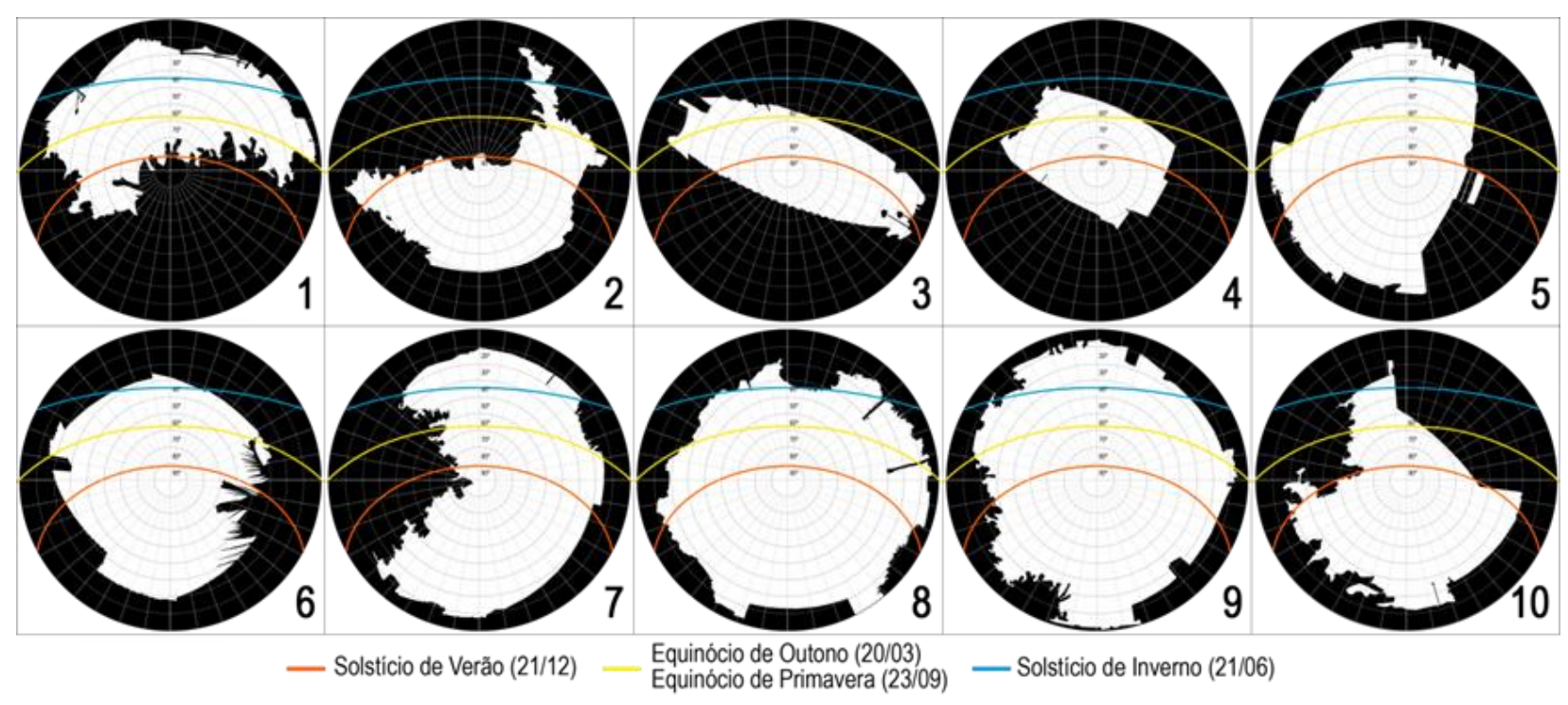

Figura 8: Gráfico de obstrução de cada uma das estações com a trajetória do sol no céu por época do ano. Fonte: Collischonn et al (2015)

As estações 3 e 4, que na Tabela 1 estão na classe alta obstrução, apresentam uma configuração similar na Figura 5. No inverno, os miniabrigos destas estações estão à sombra durante todo o dia. $\mathrm{Na}$ primavera e outono recebem insolação no final da manhã e à tarde. Durante o verão, a estação 3 já recebe radiação solar direta desde cedo, enquanto a 4 só vai recebê-la no meio da manhã. Já a estação 1, que também apresentou alta obstrução, tem uma configuração diferente; a entrada de radiação no inverno e primavera é menos obstruída e no verão é obstruída nas primeiras horas da manhã (contabiliza significativamente para esta obstrução uma árvore, com certeza mais translúcida). 
Sabe-se que a obstrução por vegetação pode apresentar comportamentos diversos ao longo do ano. Este é o caso na estação 2, que apresentou média obstrução (Tabela 1) por uma árvore caducifolia. Caso similar é o da estação 7, na qual também há uma árvore que foi cortada durante nosso período de coleta. As estações 5 e 10 de mediana obstrução apresentam uma configuração similar na silhueta da obstrução. Na 5 , há um prédio com uma parede branca a E-SE que obstrui a chegada de radiação pela manhã, mas à tarde acaba refletindo para a superfície a radiação que sobre ele incide; enquanto na 10, há um prédio a NE de cor clara que provoca reflexo da radiação à tarde. Os pontos 8 e 9 são os menos obstruídos o que propicia a entrada e saída de radiação com mais facilidade.

Para avaliar o efeito do fator de visão do céu sobre a temperatura e a umidade do ar tomamos como referência seis levantamentos de campo de temperatura e umidade relativa do ar realizados: em 2014, levantamento 1- um no inverno/primavera (27/08 a 09/09) totalizando 673 registros, levantamento 2 - na primavera (02/11a16/11) totalizando 720 registros, 3 no verão (02/12 a 16/12) totalizando 709 registros; em 2015, levantamento 4 - no verão/outono (24/02 a 17/03) totalizando 1059 registros, levantamento 5 - no outono (14/05 a 31/05) totalizando 863 registros e o último, levantamento 6 - no inverno (16/06 a 03/07) totalizando 864 registros. Neste trabalho apresentamos somente as estatísticas mais gerais (\% dos registros maiores ou menores do que a média dos 10 valores para cada momento), referentes aos dados de três campanhas de levantamento.

Na Tabela 2 apresentamos estes resultados referentes aos registros de cada um dos levantamentos de dados, numerados de 1 a 10, em conformidade com o a localização de cada miniabrigo, ainda não discriminados por tipo de tempo e momento do dia. Os dados organizados em planilha permitiram a obtenção da média de cada momento de registro para os 10 instrumentos. Com base nesta média, foi realizada uma avaliação percentual dos registros de cada um dos miniabrigos em relação a esta média que está mostrada na Tabela 2.

Nos levantamentos de dados realizados, os registros de temperatura na área central, mais intensamente urbanizada e de maior obstrução do horizonte, foram em mais de $70 \%$ das vezes superiores à média. O local que apresentou a maior percentagem de registros acima da média foi o pátio de uma farmácia no centro da cidade (ponto 4) também o de menor FVC. As áreas menos aquecidas se encontraram próximas a áreas verdes ou em menos urbanizadas. Os pontos de coleta 8 e 9 que apresentaram um maior FV foram os que apresentaram os maiores percentuais de temperatura abaixo da média nos levantamentos de primavera. Os locais mais frios que a média também foram os de umidade relativa do ar mais alta que a média. $\mathrm{O}$ instrumento registrador junto ao canal de São Gonçalo apresentou temperaturas abaixo da média, em mais de $70 \%$ dos registros, porém não foi nem o mais frio, nem o mais úmido. Portanto, constata-se o efeito do Canal de São Gonçalo como regulador térmico, pois o instrumento de coleta de número 1, localizado às margens deste, em média mostrou valores próximos à média. No entanto, a experiência de campo mostrou que, no inverno, neste ponto a sensação térmica era de temperatura bem mais baixa devido ao efeito do vento. 
Tabela 2: Porcentagem dos valores registrados a cada 30 minutos em relação à média, para cada um dos abrigos meteorológicos.

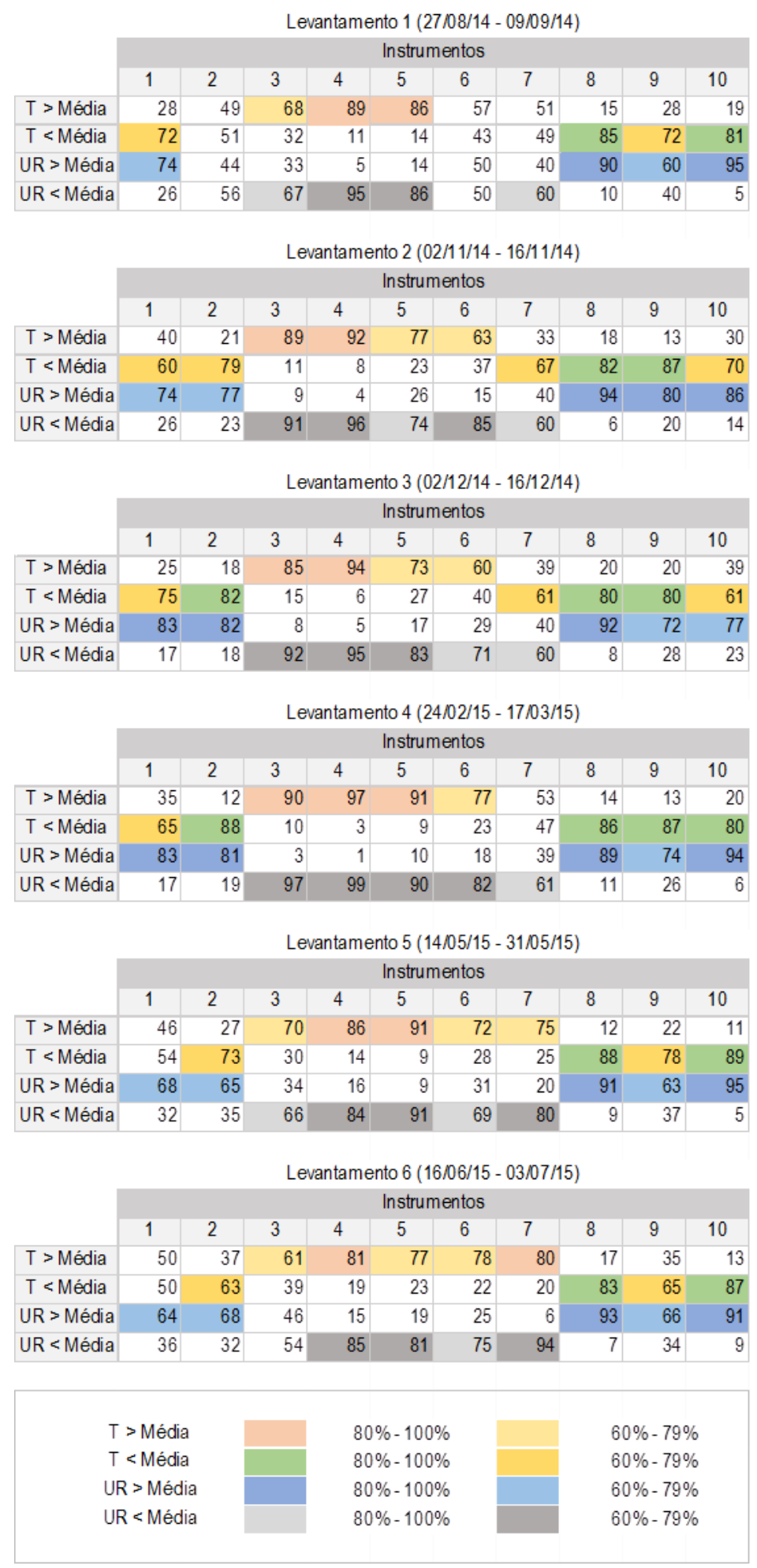




\section{CONCLUSÃO}

Apesar de já estarmos estudando o clima urbano de Pelotas há seis anos, não temos ainda uma definição completa da "resposta" local ao mecanismo da circulação regional. Com um tipo de tempo neutro a configuração a ilha de calor é clara, mas, parece haver uma relação da posição desta ilha de calor com a direção da brisa, como mostrou o experimento 1 . O segundo experimento, resultante de registros contínuos por um tempo mais longo, permitiu concluir que: há uma relação significativa entre o FVC e a temperatura do ar que se verifica não somente nas noites calmas e claras, mas na média térmica do total de dados observados. Isso parece indicar que em Pelotas, assim como foi verificado em cidades de pequeno e médio porte em outros países, o FVC é um referente fundamental para expressar os efeitos da urbanização sobre a intensidade da ilha de calor.

Com base em experimentos como os apresentados aqui, bem como em avaliações mais detalhadas das respostas conforme o tipo de tempo e o uso do solo, pretendemos chegar proximamente a etapa do diagnostico do clima urbano de Pelotas.

Ao professor Carlos Augusto de Figueiredo Monteiro agradecemos os escritos da Geosul n9, ainda que com as "receitas" ou "cartilhas" que ele aí partilhou, ele tenha contrariado toda uma postura e princípios que caracterizaram sua atividade docente (Monteiro, 1990a, p. 62). Elas foram fundamentais para nós, para os alunos e, com certeza para muitos outros aprendizes e, atrevemo-nos a dizer que, a repetição dos estudos segundo a aquelas receitas desenvolve competência e pode também levar a atividade criadora.

Talvez este processo se assemelhe ao que Perrenoud (1999) chamou de construção de habilidades e competências. No nosso modo de ver, o que Monteiro propõe nos artigos da Geosul são esquemas que orientam as operações mentais e as operações concretas, ou seja, o desenvolvimento de habilidades. O sujeito não consegue desenvolvê-las apenas interiorizando o conhecimento disponível na literatura sobre clima urbano. Concordamos com Perrenoud (2013) que competência, ou seja, a mobilização e articulação de diversos recursos cognitivos (saberes, capacidades, informações) para resolver algo de forma inovadora e criativa assegura-se tanto pela leitura como experiência vivenciada.

Tornar-se um pesquisador competente no entendimento do clima-urbano, ou seja, capaz de articular um conjunto de esquemas de percepção, pensamento, avaliação e ação requer o desenvolvimento de uma série de habilidades: (a) Compreender os requisitos básicos para a análise do campo térmico mesmo com o instrumental mais singelo; (b) Ter noção escalar para inserir a Cidade nas Unidades superiores do Clima; (c) Identificar o que é o especificamente urbano no contexto local; (d) Escolher pontos de levantamento de dados que expressem a natureza e o caráter peculiar da cidade focalizada; (e) Correlacionar as medidas feitas segundo a ótica de adentrar a cidade para inquerir sobre clima urbano, referenciando-se as medidas da observação meteorológica padrão. Portanto, só se adquire competências através de aprendizagem desenvolvida e da sua repetição, ou seja, as competências são construídas e adquiridas.

\section{REFERÊNCIAS}

AMORIM, M. C. C. T.; DUBREUIL, V. H. Q.; SANT’ANA Neto, J. L. Características das ilhas de calor em cidades de porte médio: exemplos de Presidente Prudente (Brasil) e Rennes (França), Confins [Online], 7| 2009. Disponível em: < https://confins.revues.org/6070?lang=pt> Acesso em: 21 jul. 2016.

BASCÓN, P. D. Clima, medio ambiente y urbanismo en Córdoba. Colección Estudios cordobeses. Córdoba: Ed. Diputación de Córdoba. 1999.

BORGES, K. A. de V. Curso de especialização em geoprocessamento. UFMG, 2002.

CÂMARA, G.; CASANOVA, M. A.; DAVIS Jr, C.A; VINHAS, L.; QUEIROZ, G.R.de. (Org.) Banco de Dados Geográficos. Curitiba: EspaçoGeo, 2005.

COLLISCHONN, E.; FERREIRA, C. V. O; SILVEIRA, R. S. 2015. O fator de visão do céu e sua influência sobre as características térmico-higrométricas intraurbanas em Pelotas/RS, Brasil, Geographia Meridonalis, $1(1), \quad$ p.160-178, 2015.20 Disponível <https://periodicos.ufpel.edu.br/ojs2/index.php/Geographis> Acesso em: 12 ago. 2016.

GARTLAND, L. Ilhas de calor - como mitigar zonas de calor em áreas urbanas. ( Tradução de Silvia Helena Gonçalves). São Paulo: Oficina de Textos, 2010.

HÄMMERLE, M.; GÁL,T; JUNGER, J; MATZARAKIS, A. Introducing a script for calculating the sky view factor used for urban climate investigations. Acta Climatologica et Chorologica, n. 44-45, p.83-92, 
2011. Disponível em: < http://www2.sci.u-szeged.hu/eghajlattan/akta11/index.html> Acesso em: 12 ago. 2015.

HASENACK, H.; CORDEIRO, J.L.P; HOFMANN, G.S. O Clima da RPPN SESC Pantanal. UFRGS - IB Centro de Ecologia. Relatório técnico. Porto Alegre, 2003.

HASENACK, H.; SCHMIDT J.; BECKE, V.L. 1982. Distribuição noturna da temperatura em Porto Alegre. In: Encontro Nacional de Geógrafos, 5, 1982, Porto Alegre. Anais...Porto Alegre, 1982, p.438-.

INSTITUTO BRASILEIRO DE GEOGRAFIA E ESTATÍSTICA - IBGE. Censo demográfico 2010. Disponível em: <http://www.ibge.gov.br/home/estatistica/populacao/censo2010/> Acesso em 5 set. 2015.

LINDBERG, F., HOLMER, B. Sky View Factor Calculator - User Manual - Version 1.1. Göteborg Urban Climate Group - Department of Earth Sciences - University of Gothenburg, 2010. 4p. Disponível em: < http://www.gu.se/digitalAssets/1337/1337400_skyviewfactorcalculator-user-manual.pdf> Acesso em: 21 jun. 1996.

LONGLEY, Paul; GOODCHILD Michael E.; MAGUIRE, David J., RHIND David W. Sistemas e Ciência da Informação Geográfica. (Tadução - $3^{\circ}$ Edição) Porto Alegre: Bookman, 2013. 560p

MARINHA DO BRASIL. Cartas Sinóticas. 2015. Disponível em: <https://www.mar.mil.br/dhn/ $\mathrm{chm} / \mathrm{meteo} / \mathrm{prev} / \mathrm{cartas} / \mathrm{cartas} . \mathrm{htm}>$. Acesso em: 13 set. 2015.

METSUL - Blog - Meteorologia. Disponível <http://www.metsul.com/> Acesso em: 13 set 2015.

MINELLA, F. C. O.; ROSSI, F. A.; KRÜGER, E. L. Análise do efeito diurno do fator de visão do céu no microclima e nos níveis de conforto térmico em ruas de pedestres em Curitiba. Ambiente Construído, 11(1), p.123-143, 2011.

MIRANDA, J. I. Fundamentos de Sistemas de Informações Geográficas. Brasília: Embrapa Informação Tecnológica, 2005.

MONTEIRO, C. A. F. Adentrar a cidade para tomar-lhe a temperatura. Geosul, n. 9, ano 5. Florianópolis: Edufsc p. 61-79, 1990a

MONTEIRO, C. A. F. A cidade como processo derivado ambiental e a geração de um clima urbano: estratégias na abordagem geográfica. Geosul, n. 9, ano V. Florianópolis: Edufsc, p. 80-114, 1990b

MONTEIRO, C. A. de F. Teoria do clima urbano: Um projeto e seus caminhos. In: MONTEIRO, C.A de F; MENDONÇA. (org). Clima Urbano. São Paulo: Editora Contexto, 2003. p.9-67.

Oke, T. R.. Boundary Layer Climates. London: Methuen, 1987.

Oke, T.R. Initial Guidance to Obtain Representative Meteorological Observations at Urban Sites. IOM Report No.81, WMO/TD. No. 1250. World Meteorological Organization, Geneva, 2006.

PERRENOUD, Phillip. Construir as competências desde a escola. Porto Alegre: Artmed, 1999.

PERRENOUD, Phillip. Desenvolver Competências ou Ensinar Saberes? A Escola que Prepara a Vida. Porto Alegre: Penso, 2013

QGIS. Documentação do QGIS2.8. 2014. Disponível em: <http://www.qgis.org/en/docs/ index.html\#> Acesso em: 24 set. 2015.

SWENSON, M. K. Sky view factor analysis - implications for urban air temperature differences. Meteorological Applications, 11 (3), set. 2004. p.201-211. Disponível em < http://onlinelibrary.wiley.com/doi/10.1002/met.v11:3/issuetoc> Acesso em: 24 ago. 2015. 